Article

\title{
Quantitative Proteomics to Identify Nuclear RNA-Binding Proteins of Malat1
}

\author{
Marian Scherer, Michal Levin, Falk Butter and Marion Scheibe * \\ Institute of Molecular Biology (IMB), Ackermannweg 4, 55128 Mainz, Germany; \\ mscher04@students.uni-mainz.de (M.S.); m.levin@imb.de (M.L.); f.butter@imb.de (F.B.) \\ * Correspondence: m.scheibe@imb.de
}

Received: 31 December 2019; Accepted: 6 February 2020; Published: 10 February 2020 updates

\begin{abstract}
The long non-coding RNA Malat1 has been implicated in several human cancers, while the mechanism of action is not completely understood. As RNAs in cells function together with RNA-binding proteins (RBPs), the composition of their RBP complex can shed light on their functionality. We here performed quantitative interactomics of 14 non-overlapping fragments covering the full length of Malat1 to identify possible nuclear interacting proteins. Overall, we identified 35 candidates including 14 already known binders, which are able to interact with Malat1 in the nucleus. Furthermore, the use of fragments along the full-length RNA allowed us to reveal two hotspots for protein binding, one in the $5^{\prime}$-region and one in the $3^{\prime}$-region of Malat1. Our results provide confirmation on previous RNA-protein interaction studies and suggest new candidates for functional investigations.
\end{abstract}

Keywords: quantitative interactomics; lncRNA; RNA-binding proteins; Malat1

\section{Introduction}

Mass spectrometry-based proteomics allows identifying thousands of proteins in a single experiment and has been instrumental for screens to identify unknown interaction partners in affinity purification experiments. The first quantitative RNA-protein interaction screens were conducted with in vitro transcribed RNA structures and fragments of mRNA [1,2]. Later, alternative approaches provided catalogues of RNA-binding proteins (RBPs) purified from in vivo cross-linked RNA combined with poly-A capture [3,4] and have been complemented by techniques like capture hybridization analysis of RNA targets and mass spectrometry (CHART-MS), comprehensive identification of RNA-binding proteins by mass spectrometry (ChIRP-MS), and RNA antisense purification and mass spectrometry (RAP-MS) [5-8] that affinity capture a single target RNA from the in vivo cellular environment using hybridization probes. These and other proteomics strategies have been applied to non-coding RNAs [9].

Metastasis-associated lung adenocarcinoma transcript 1 (Malat1 or MALAT1) or also known as noncoding nuclear enriched abundant transcript 2 (neat2 or NEAT2) was originally discovered as a marker to predict metastasis and survival in early-stage non-small cell lung cancer [10]. MALAT1 deregulation has since then been noted in several human cancers [11,12]. It is a highly transcribed, mostly nuclear transcript with very strong evolutionary conservation in mammals [13], a commonly suggested hallmark of functional importance. The MALAT1 lncRNA precursor transcript in humans has a length of $8779 \mathrm{nt}$ (refseq: NR_002819) and is processed into a full-length lncRNA transcript of ca. $8 \mathrm{~kb}$ that localizes to nuclear speckles [14] and a $61 \mathrm{nt}$ mascRNA (MALAT1-associated small cytoplasmic RNA) that functions in the cytoplasm [15].

The long noncoding RNA has been involved in splicing, transcriptional, and posttranscriptional regulation [16]. The interaction of IncRNAs with proteins is one possible mechanism for their functionality, 
for example by acting as a scaffold to bring proteins of different functionality together $[17,18]$. Thus, several studies using different strategies have been conducted to identify the RBP interactome of MALAT1. From protein-centric studies (mostly CLIP experiments) of known RNA binding proteins, human MALAT1 has been reported to interact with the PRC2 complex acting in transcription repression via methylation of H3K27 [19] as well as with the splicing factor SRSF1 [20,21]. In addition, several RNA-centric approaches have been applied already. A recent SILAC-based RNA interaction screen reported 127 enriched proteins using the 6918-8441 nt fragment of human MALAT1 and unveiled that interaction of DBC1 with this IncRNA does sequester DBC1 from SIRT1 and thereby influences p53 acetylation [22]. Furthermore, human MALAT1 was one target in the recently described multiplexed hybridization purification of RNA-protein complexes for mass spectrometry (HyPR-MS) approach that identified 127 interaction partners to the full-length human transcript [23]. Using ChIRP-MS, another group identified 23 interactors of murine Malat1, including the TEAD proteins whose interaction with Malat1 inhibits their transcriptional activity [24]. While MALAT1 is one of the more highly conserved lncRNAs, overall conservation of IncRNA is not comparable to protein-coding genes. We thus here applied RNA pulldown assays coupled to quantitative mass spectrometry to investigate interaction partners of 14 non-overlapping fragments of murine Malat1 with the aim of (1) investigating whether factors reported previously to be able to bind to human MALAT1 are conserved, (2) focus on the pool of RBPs that are able to interact with Malat1 in the nucleus, and (3) to obtain spatial information of the RBP binding pattern along Malat1.

\section{Results}

\subsection{Setup of a Quantitative RNA-Protein Interaction Screen for the Long Non-Coding RNA Malat1}

We decided to measure the RBP interactome for the nuclear $6983 \mathrm{nt}$ murine Malat1 by dividing the lncRNA into 14 fragments of 500 bases each (the last one being $483 \mathrm{nt}$ ). Each fragment was amplified by PCR using primers that contained the sequence for the T7 promoter at the $5^{\prime}$-end and the S1 aptamer sequence at the $3^{\prime}$-end (Figure 1). All 14 fragments were in vitro transcribed using T7 RNA polymerase and coupled to paramagnetic streptavidin beads prior to incubation with nuclear extract of the murine NSC-34 neuroblastoma cell line. To perform quantitative comparison against a non-related RNA fragment, we in vitro transcribed a longer version of the region of the pDEST17 vector (469 nt) used as control also in a previous study [2].

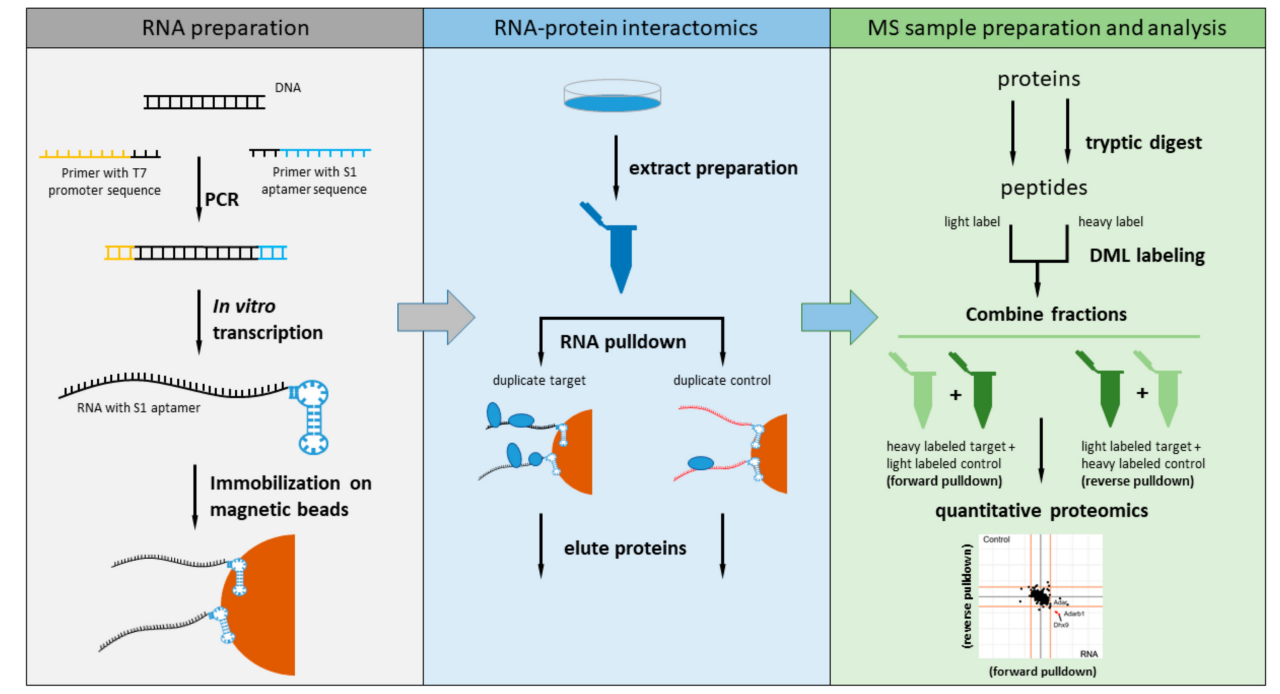

Figure 1. Schematic overview of our quantitative RNA-protein interaction screen of Malat1. RNA fragments of 500 bases length fused with the S1 biotin aptamer at their $3^{\prime}$-end were expressed in vitro, immobilized on paramagnetic streptavidin beads, and then incubated with nuclear enriched lysate. The bound proteins were analyzed by mass spectrometry-based quantitative proteomics. 
The RNA pulldown for each Malat1 fragment and the non-related control RNA was performed twice in parallel to allow incorporation of a label switch during the reductive dimethylation. Unbound proteins were removed by washing and the bound protein fraction eluted with LDS sample buffer. Each pulldown was subjected to tryptic digest and reductive dimethyl labeling prior to mass spectrometry analysis on a high-resolution mass spectrometer.

\subsection{Quantitative Interactomics of the Malat1 Fragments}

The data was analyzed with MaxQuant [25] and for each of our Malat1 fragment the quotient of the protein enrichment ratio of the two dimethyl labels was calculated. A forward and reverse experiment were plotted against each other to generate a two-dimensional interaction plot, in which proteins enriched at the Malat1 fragment are shown in the lower right quadrant (Figure 2). Most of the quantified proteins were found to be binding equally well to Malat1 and our control fragment demonstrated by their clustering around the origin of the plot. Notably, across all fragments this background cloud was clearly defined and we thus decided to score RBPs as enriched when their ratio between Malat1 and the control exceeded 1.7-fold (Supplemental Figures S1 and S2).

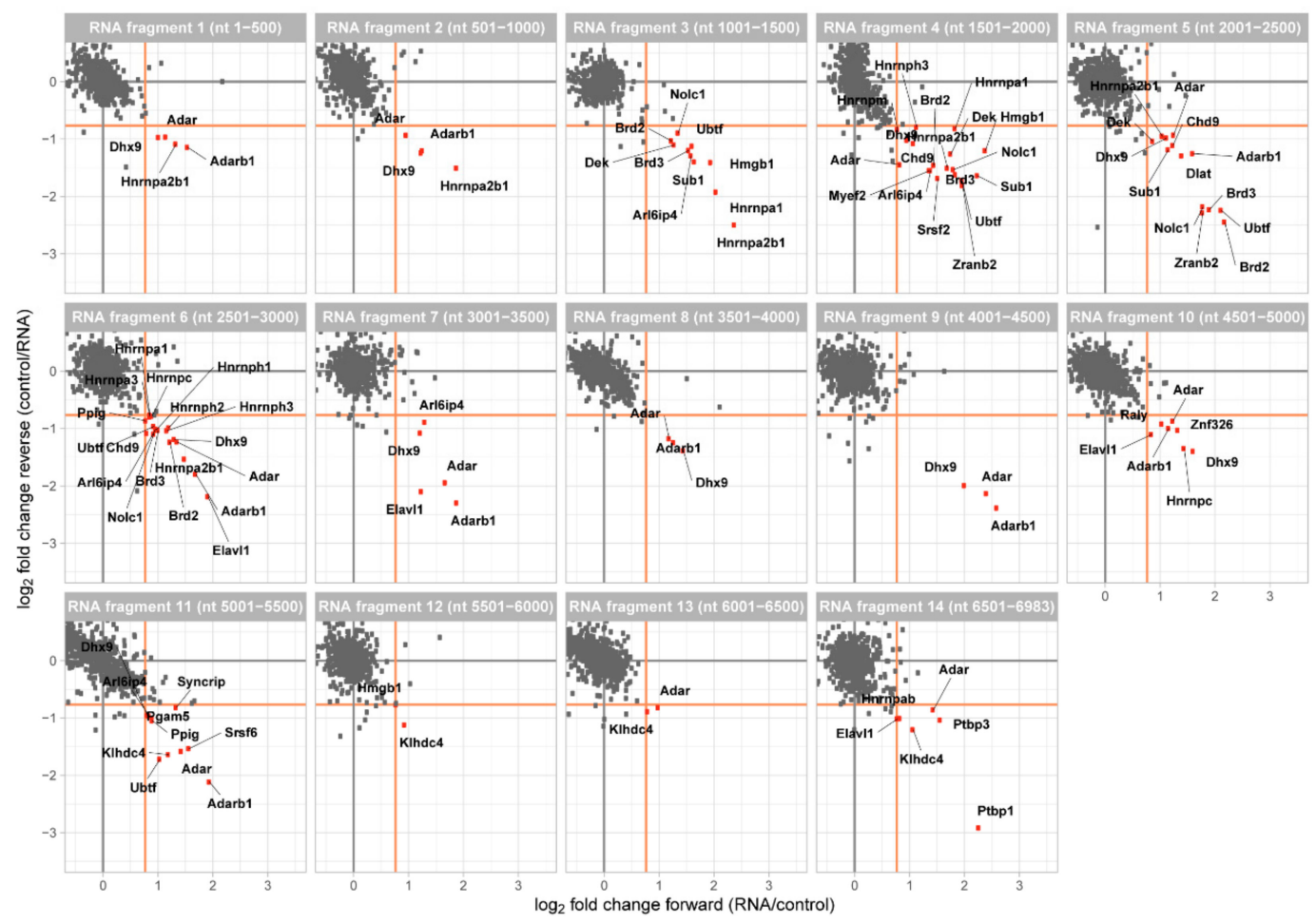

Figure 2. Two-dimensional interaction plot for each of the 14 RNA fragments. Fragments are numbered consecutive from $5^{\prime}$ to $3^{\prime}$ of murine Malat 1 and their position within the lncRNA is indicated. Enriched proteins (fold change $>1.7$, orange line) are marked in red and annotated.

At this enrichment threshold, we were able to identify enriched proteins at each fragment of Malat1. In agreement with the use of nuclear extracts, 33 of them have been described to localize to the nucleus and 2 were assigned to the mitochondrion. Furthermore, 29 proteins are known to bind to RNA and 20 of them have an annotated RNA recognition domain. Overall, we identified 35 different proteins (Table 1) and the interactors are functionally associated with mRNA processing, RNA splicing, RNA metabolic processes, and gene regulation. These Malat1-enriched interactors include hnRNPs, splicing factors, chromatin remodelers, and RNA editing enzymes. 
Table 1. List of the proteins found to be enriched at murine Malat1. Proteins marked in bold were already known to interact with human or mouse MALAT1 from previous studies. Proteins with a gene ontology annotation for RNA-binding are shaded in grey.

\begin{tabular}{|c|c|c|}
\hline Protein & Name/Function & Primary Localization \\
\hline Adar1 & dsRNA specific RNA deaminase & Nuclear \\
\hline Adarb1 & dsRNA specific editase & Nuclear \\
\hline Arl6ip4 & modulating alternative pre-mRNA splicing & Nuclear \\
\hline $\operatorname{Brd} 2$ & binds hyperacetylated histones, regulation of transcription & Nuclear \\
\hline Brd3 & binds hyperacetylated histones, regulation of transcription & Nuclear \\
\hline Chd9 & transcriptional coactivator and putative chromatin remodeler & Nuclear \\
\hline Dek & chromatin organization & Nuclear \\
\hline Dhx9 & multifunctional RNA helicase & Nuclear and cytoskeleton \\
\hline Dlat & dihydrolipoamid S-acetyltransferase & Mitochondrial \\
\hline Elavl1 & HuR antigen, binds and stabilizes mRNA & Nuclear \\
\hline Hmgb1 & high mobility group protein $B 1$ & Nuclear and endosome \\
\hline Hnrnpa1 & heterogeneous nuclear ribonucleoprotein A1 & Nuclear \\
\hline Hnrnpa2b1 & heterogeneous nuclear ribonucleoprotein A2B1 & Nuclear and extracellular \\
\hline Hnrnpa3 & heterogeneous nuclear ribonucleoprotein A3 & Nuclear \\
\hline Hnrnpab & heterogeneous nuclear ribonucleoprotein $A B$ & Nuclear \\
\hline Hnrnpc & heterogeneous nuclear ribonucleoprotein C & Nuclear \\
\hline Hnrnph1 & heterogeneous nuclear ribonucleoprotein $\mathrm{H1}$ & Nuclear \\
\hline Hnrnph2 & heterogeneous nuclear ribonucleoprotein $\mathrm{H} 2$ & Nuclear \\
\hline Hnrnph3 & heterogeneous nuclear ribonucleoprotein $\mathrm{H} 3$ & Nuclear \\
\hline Hnrnpm & heterogeneous nuclear ribonucleoprotein $\mathbf{M}$ & Nuclear \\
\hline Klhdc4 & kelch domain-containing protein 4 & Nuclear \\
\hline Myef2 & transcriptional repressor of the myelin basic protein gene & Nuclear \\
\hline Nolc1 & regulator of RNA polymerase I & Nuclear \\
\hline Pgam5 & serine/threonine phosphatase & Mitochondrial \\
\hline Ppig & peptidyl-prolyl cis-trans isomerase G, pre-mRNA splicing & Nuclear \\
\hline Ptbp1 & pre-mRNA splicing and regulation of alternative splicing & Nuclear \\
\hline Ptbp3 & pre-mRNA alternative splicing & Nuclear \\
\hline Raly & possible heterogeneous nuclear ribonucleoprotein & Nuclear \\
\hline Srsf2 & serine/arginine-rich splicing factor 2 & Nuclear \\
\hline Srsf6 & serine/arginine-rich splicing factor 6 & Nuclear \\
\hline Sub1 & coactivator that functions cooperatively with TAFs & Nuclear \\
\hline Syncrip & heterogeneous nuclear ribonucleoprotein $\mathrm{Q}$ & Nuclear and ER \\
\hline Ubtf & nucleolar transcription factor binding rRNA gene promoter & Nuclear \\
\hline Zfp326 & core component of DBIRD complex, alternative splicing & Nuclear \\
\hline Zranb2 & splice factor required for alternative splicing & Nuclear \\
\hline
\end{tabular}

\subsection{Binding Pattern of Interactors along Malat1}

The binding pattern of the individual proteins ranged from very specific (only enriched with one fragment) to ubiquitous (enriched at all fragments). The number of enriched proteins varied between only 2 enriched interactors for fragment 13 to 20 interactors for fragment 4 and fragment 6. We performed unsupervised clustering of these enriched proteins to investigate whether there is an overall dependency for co-binding and indeed identified 3 major clusters (Figure 3). In the first cluster, we found proteins that are nearly exclusively enriched between fragment 3 and fragment 6 , corresponding to 1001-3000 nt of Malat1. In this cluster, we find the heterogeneous RNA binding proteins (Hnrnpa1, Hnrnpa2b1, and Hnrnpa3), proteins involved in chromatin organization (Dek and Hmgb1), transcription (Sub1 and Ubtf), and splicing (Arl6ip4, Brd2, Brd3, Srsf2, and Zranb2). Some proteins are part of complexes, like the spliceosome or have been reported to co-immunoprecipitate in large-scale protein-protein interaction studies; e.g., ARL6IP4/ZRANB2 and BRD2/BRD3 in human HEK293T cells [26].

The second cluster contains all interactors whose binding is distributed across all studied fragments. In addition, here, with Hnrnpab, Hnrnph1, Hnrnph2, Hnrph3, Hnrnpm, Hnrnpc, and Hnrnpq (also known as Syncrip), and the possible group member Raly, the hnRNPs form a large group of interactors. In this group, we also find the splicing factor Srsf6 and the splicing enzyme Ppig, the transcriptional regulators Chd9 and Myef2, the polypyrimidine-tract binding proteins Ptbp1 and Ptbp3, the RNA stability regulator Elavl1 (also known as HuR), the core DBIRD complex member Zfp326 and the uncharacterized kelch domain-containing protein Klhdc4. Two other proteins, Dlat and Pgam5 are 
reported mitochondrial proteins and while they are detected to be enriched at two different fragments of Malat1, they might not interact with the lncRNA in the nucleus.

In the third cluster, we obtained only 3 proteins (Adar1, Adarb1, and Dhx9). This cluster contains all proteins with broad binding pattern along Malat1, which consequently were enriched on at least 9 of the 14 fragments. These three proteins, one multi-specific RNA helicase and the Adar1/Adarb1 editosome, are nuclear localized and are likely to bind to a large number of cellular RNAs. We might have enriched for these less specific binding proteins through the comparison to an unrelated RNA control sequence that originated from a randomly chosen region of a vector.

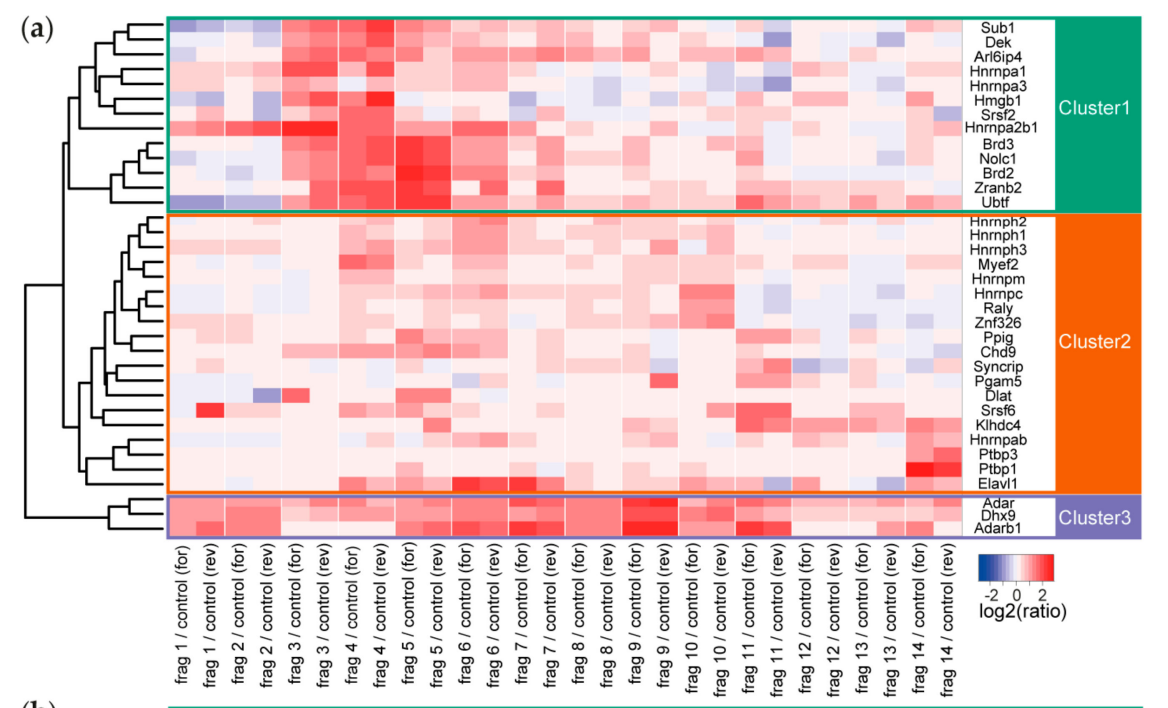

(b)

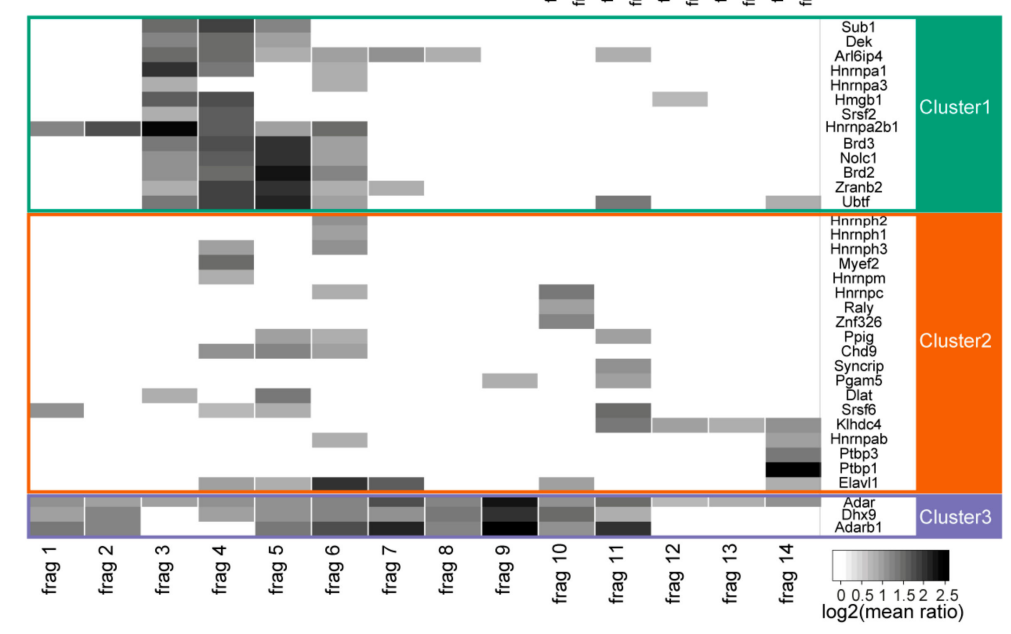

Figure 3. (a) Heatmap of all values for the enriched RNA-binding proteins at all Malat1 fragments (including the forward and reverse experiment). Cluster tree on the left edge reveals three major clusters representing different binding patterns of the interactors. (b) Filtered heatmap representation of the interactors only when fulfilling the 1.7-fold enrichment threshold.

\subsection{Structure of MALAT1}

At least some lncRNAs have been shown to exert their scaffold function by smaller domains as was shown with HOTAIR previously [18]. We thus investigated, whether our detected interactors hint towards functional separated domains in Malat1. Performing network analysis of our 14 fragments, we found that there is a strong correlation among fragments 1-2, 3-4, 6-10, and also fragments 11 and 13, with a slight anti-correlation between parts of the $5^{\prime}$-region (fragment $3-5$ ) and the $3^{\prime}$-region (fragment 6-14) of Malat1 (Figure 4). Notably, the fragments 3-6 (1001-3000 nt) in the $5^{\prime}$-region and the fragments 10-11 (4501-5500 nt) in the $3^{\prime}$-region were identified as hotspots for the binding of proteins. 


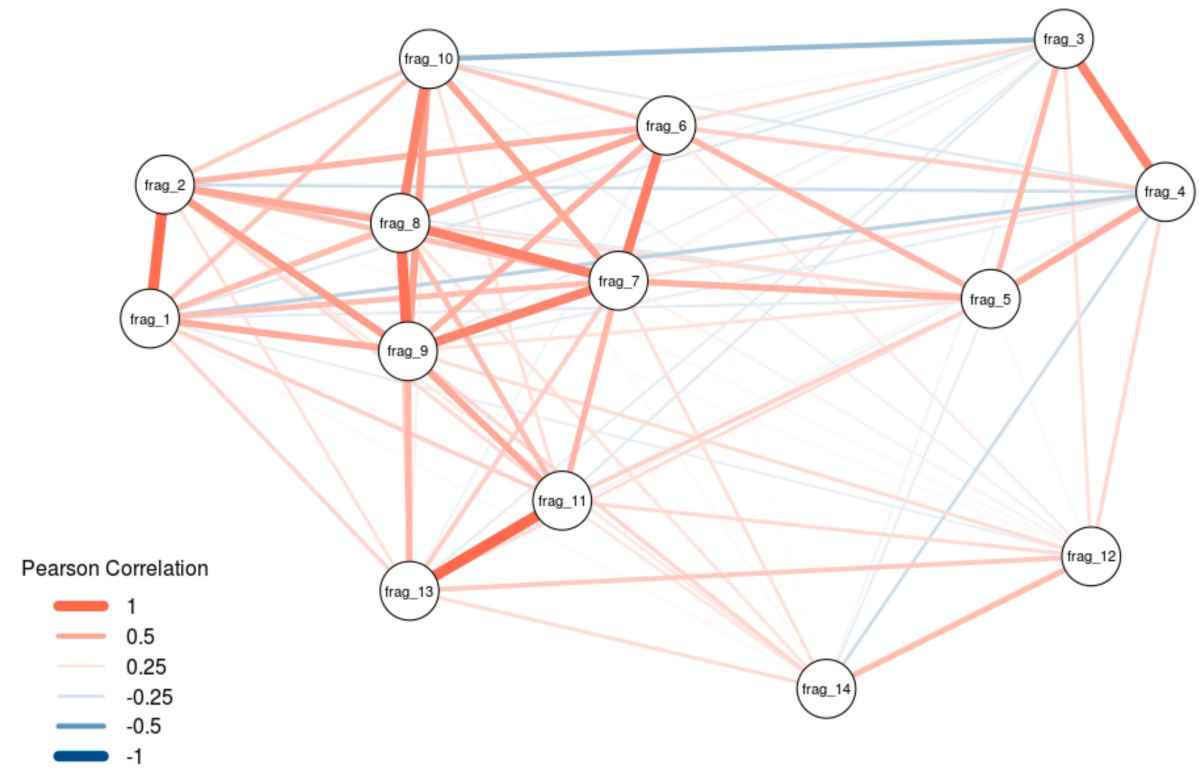

Figure 4. Weighted network diagram describing the resemblance of binding patterns of the different RNA fragments. Nodes represent RNA fragments. Thickness and length of edges connecting nodes correspond to the pairwise Pearson correlation coefficient between the protein enrichments of two RNA fragments. Red and blue colors correspond to positive and negative correlations, respectively.

To note, our analysis shows the highest correlation exclusively with adjacent fragments and anti-correlation is only seen when the fragments are not consecutive. This strongly suggests that the detected protein interaction pattern is not random and shows that Malat1 has regions with similar binding behavior, suggesting possible functional domains.

\section{Discussion}

We performed a quantitative RNA-protein interaction screen using an in vitro RNA pulldown approach for Malat1 with nuclear extract from the murine NSC-34 neuroblastoma cell line. By enrichment analysis, we identified 35 proteins to be able to interact with nuclear Malat1.

A similar quantitative RNA pulldown approach has been performed previously with a fragment of human MALAT1 applying stable isotope labeling of amino acids in cell culture (SILAC) as the quantitative strategy. In contrast to this previous experiment that mapped interactors only at a proposed physiological relevant fragment (nt 6918-8441) of human MALAT1, we here mapped interactors to the complete sequence of mouse Malat1 using 14 fragments of $500 \mathrm{nt}$ each. Additionally, we here used nuclear extract instead of whole cell lysate as the lncRNA Malat1 is localized in the nucleus. While the quantitative proteomic strategies are likely interchangeable, the use of shorter fragments, a cell line originating from a different tissue, a nuclear extract and the study of murine Malat1 are sufficient differences to justify slightly diverse results. Comparing our 35 proteins to the human set of 127 interactors, we found overlap for 10 proteins (Dhx9, Hnrnpa3, Ptbp1, Elavl1, Hnrnpc, Adar, Hnrnpa2b1, Hnrnph1, Hnrnpm, and Hnrnpab), nearly one third of our candidates. Notably, other candidates from the human MALAT1 experiment are cytoplasmic and it is not clear how relevant they are for the function of MALAT1 given its nuclear localization.

Especially noteworthy is that according to conservation analysis the $3^{\prime}$-end of human MALAT1 would be similar to the $5^{\prime}$-end of murine Malat1 [27]. Here again, as in most of the lncRNA world, our understanding of conservation is not as easily applicable as for protein domains. Nevertheless, in general, we find that the hnRNPs involved in (alternative) splicing regulation are able to bind to MALAT1 in both species. In fact, interaction with HNRNPH1 and HNRNPH2 has been shown for human MALAT1 and HNRNPC binding has been mapped to several different fragments of human MALAT1 [28]. 
In addition to RNA pulldown approaches, oligonucleotide capture experiments have been conducted to obtain RBP interactomes for the complete full-length lncRNA: HyPR-MS for human MALAT1 [23] and ChIRP-MS for murine Malat1 [24]. Our overlap to both experiments is not very high. In the case of the HyPR-MS experiment, we at least overlap for HNRNPH2 and SRSF6; for ChIRP-MS, we have no overlap to the identified 23 interactors. This is not so surprising, as the used techniques are completely different in their experimental strategy and have different limitations. All screens for example, missed the reported interaction of MALAT1 with PRC2 [19].

In our screen, we found candidates that were already functionally associated to either mouse or human MALAT1. This includes the interaction with SRSF2, which has a described functional role in the alternative splicing regulation of MALAT1 [20,29]. Furthermore, we recover the link to the interaction of MALAT1 with DBC1 [22]. While we did not directly enrich DBC1 as an interactor of Malat1, we identified Zfp326 that interacts directly with DBC1 [30,31]. We also detected binding of Elavl1 (also known as HuR) to MALAT1 previously reported to form a complex that represses transcription [32]. Thus, our screen recovered already known interactors, mostly characterized for human MALAT1 also for Malat1 in mouse.

There are some not yet known interactors in our screen that might be interesting candidates for future functional studies. Among the candidates unique to our study are several proteins described to be involved in different cancer types in humans: for example, NOLC1 in multidrug resistant non-small cell lung cancer (the same cancer MALAT1 has originally been identified) [33], DEK in breast cancer [34] and SUB1 in prostate cancer [35]. Intriguingly, we found two bromodomain containing proteins (BRD2 and BRD3) noted to be relevant in cancer [36] interacting with MALAT1. Bromodomains are known to interact with acetylated lysine residues and the second bromodomain of BRD2 is able to bind acetylate histone lysine residues [37], providing a means of Malat1 to be recruited to active genes [6].

One advantage of the RNA pulldown approach is the ability to dissect a long RNA into smaller fragments to identify putative functional domains. We here used 14 fragments of $500 \mathrm{nt}$ length to scan changes in the RBP interactome of Malat1. We identified two hotspots for interaction: fragment 3-6 (nt 1001-3000) and fragment 10-11 (nt 4501-5500). Most of our enriched interaction partners are found at these two regions. This suggests that murine Malat1 might have two distinct domains that provide interaction interfaces for proteins or protein complexes that should be tested functionally in the future.

\section{Materials and Methods}

\subsection{Cloning of Malat1 from Murine NSC-34 cells}

Total RNA was isolated from murine NSC-34 cells using the PrepEase RNA Spin Kit (USB, Cleveland, OH, USA) followed by cDNA preparation with the RevertAid First Strand cDNA Synthesis Kit (Thermo Fisher Scientific, Waltham, MA, USA) according to the manufacturer's instruction. Malat1 fragments were amplified using Pfu Ultra II Fusion HS DNA polymerase (Agilent, Santa Clara, CA, USA) with specific amplification primers (Supplemental Table S1) and cloned into $\mathrm{pCR} 8$ vector using the pCR8/GW/TOPO TA Cloning Kit (Thermo Fisher Scientific, Waltham, MA, USA).

Inserts were validated by Sanger sequencing (Eurofins Genomics, Ebersberg, Germany). The fragment sequences were fused to the T7 promoter sequence at the $5^{\prime}$-end and the minimal S1 aptamer sequence [38] at the $3^{\prime}$-end by a PCR reaction using fragment specific primers (Supplemental Table S2). The control fragment was amplified from a pDEST17 vector (Thermo Fisher Scientific, Waltham, MA, USA) using OneTaq DNA polymerase (NEB, Ipswich, MA, USA), a forward primer containing the T7 promoter sequence and a reverse primer with the minimal S1 aptamer sequence (Supplemental Table S2).

\subsection{In Vitro Transcription of RNA Fragments}

In vitro transcription was performed for $4 \mathrm{~h}$ at $37^{\circ} \mathrm{C}$ using 200 units of T7 RNA polymerase (Thermo Fisher Scientific, Waltham, MA, USA) in the supplied transcription buffer containing $13 \mathrm{mM}$ 
NTPs and $1 \mu \mathrm{g}$ DNA template. Successful transcription was monitored by agarose gel electrophoresis. RNA was purified by phenol-chloroform extraction. To this end, the transcription reaction was combined with nuclease free water to a final volume of $250 \mu \mathrm{L}$. Then, $400 \mu \mathrm{L}$ Phenol/Chloroform 5:1 pH 4.3-4.7 (Sigma Aldrich, St. Louis, MO, USA) was added and the mixture was vortexed. After centrifugation for $3 \mathrm{~min}$ at 10,000 rpm (Fresco centrifuge, Thermo, Waltham, MA, USA), the upper phase was transferred into a new reaction tube and $1 \mathrm{~mL}$ pure ethanol (Sigma Aldrich, St. Louis, MO, USA) containing $15 \mu \mathrm{g} / \mathrm{mL}$ GlycoBlue (Ambion, Austin, TX, USA) was added and mixed. The sample was incubated for $10 \mathrm{~min}$ at $-80^{\circ} \mathrm{C}$ and centrifuged afterwards for $1 \mathrm{~h}$ at $4{ }^{\circ} \mathrm{C}$ and $14,000 \mathrm{rpm}$ (Fresco centrifuge, Thermo Fisher Scientific, Waltham, MA, USA). The RNA pellet was dried for 5 min at room temperature and resuspended in nuclease free water. RNA concentration was determined by measuring the extinction at $260 \mathrm{~nm}$ with a Nanodrop 2000 spectral photometer (Thermo Fisher Scientific, Waltham, MA, USA).

\subsection{Preparation of Nuclear Extracts}

NSC-34 cells were grown in DMEM media (Thermo Fisher Scientific, Waltham, MA, USA) containing 10\% FBS (Thermo Fisher Scientific, Waltham, MA, USA) and $100 \mathrm{U} / \mathrm{mL}$ penicillin and $100 \mu \mathrm{g} / \mathrm{mL}$ streptomycin (Sigma Aldrich, St. Louis, MO, USA) in a humidified incubator at $37^{\circ} \mathrm{C}, 5 \%$ $\mathrm{CO}_{2}$, and $70 \%$ humidity. Nuclear extracts were prepared basically as described previously [39]. In short, harvested cells were washed in 1x PBS (Thermo Fisher Scientific, Waltham, MA, USA), incubated in five pellet volumes of cold buffer A (10 mM HEPES-KOH pH 7.9, $1.5 \mathrm{mM} \mathrm{MgCl} 2,10 \mathrm{mM} \mathrm{KCl})$ for $10 \mathrm{~min}$ on ice and collected by centrifugation. Cells were resuspended in two volumes of cold buffer A containing 0.1\% IGEPAL CA-630 (Sigma Aldrich, St. Louis, MO, USA), 0.5 mM DTT, and a protease inhibitor mix (1 $\mu \mathrm{M}$ Pepstatin A [SERVA Electrophoresis GmbH, Heidelberg, Germany], $1 \mu \mathrm{g} / \mathrm{mL}$ Leupeptin [SERVA Electrophoresis GmbH, Heidelberg, Germany], and $1 \mathrm{mM}$ PMSF [SERVA Electrophoresis $\mathrm{GmbH}$, Heidelberg, Germany]) and sheared with 50 strokes (type B pestle) in a dounce homogenizer. After centrifugation for $15 \mathrm{~min}$ at $3900 \mathrm{rpm}$ (Multifuge X3R, Thermo Fisher Scientific, Waltham, MA, USA) at $4{ }^{\circ} \mathrm{C}$, pelleted nuclei were resuspended in two volumes of buffer C (420 mM $\mathrm{NaCl}, 20$ mM HEPES-KOH pH 7.9, 20\% glycerol, 2 mM MgCl, 0.2 mM EDTA pH 8.0, 0.1\% IGEPAL CA-630, $0.5 \mathrm{mM}$ DTT, and protease inhibitor mix). Subsequently the suspension was incubated for $1 \mathrm{~h}$ on a rotating wheel at $4{ }^{\circ} \mathrm{C}$ and centrifuged at 14,500 rpm (Fresco centrifuge, Thermo Fisher Scientific, Waltham, MA, USA) for $1 \mathrm{~h}$ at $4{ }^{\circ} \mathrm{C}$ to obtain the nuclear extract as supernatant. The protein concentration was established by Bradford (Bio-rad, Hercules, CA, USA) using an UV/Vis photometer (Amersham Bioscience, Freiburg, Germany).

\subsection{RNA Pulldown}

For each pulldown, $25 \mu \mathrm{g}$ S1-tagged RNA was immobilized on $50 \mu \mathrm{L}$ paramagnetic streptavidin beads (Dynabeads C1, Thermo Fisher Scientific, Waltham, MA, USA) in RNA binding buffer (100 mM $\mathrm{NaCl}, 50$ mM HEPES-KOH pH 7.6, 0.1\% IGEPAL CA-630, 10 mM MgCl $2,1 \mu \mathrm{M}$ Pepstatin A, $1 \mu \mathrm{g} / \mathrm{mL}$ Leupeptin, and $1 \mathrm{mM}$ PMSF) at $4{ }^{\circ} \mathrm{C}$ for $30 \mathrm{~min}$ on a rotation wheel. After two washing steps with RNA binding buffer to remove excess unbound RNA, the prepared beads were incubated with $400 \mu \mathrm{g}$ nuclear extract and $20 \mu \mathrm{g}$ yeast tRNA (Thermo Fisher Scientific, Waltham, MA, USA) as competitor in RNA wash buffer (250 mM NaCl, 50 mM HEPES-KOH pH 7.6, 0.1\% IGEPAL CA-630, 10 mM MgCl , $1 \mu \mathrm{M}$ Pepstatin A, $1 \mu \mathrm{g} / \mathrm{mL}$ Leupeptin, and $1 \mathrm{mM}$ PMSF) for $30 \mathrm{~min}$ and $4{ }^{\circ} \mathrm{C}$ on a rotation wheel. Unbound proteins were removed by three washing steps with $200 \mu \mathrm{L}$ RNA washing buffer and bound proteins eluted by heating beads in $1 \times$ LDS Buffer (Thermo Fisher Scientific, Waltham, MA, USA) supplemented with $100 \mathrm{mM}$ DTT for $10 \mathrm{~min}$ at $70^{\circ} \mathrm{C}$ and $1400 \mathrm{rpm}$ in a thermomixer (Eppendorf, Hamburg, Germany). 


\subsection{Mass Spectrometry Sample Preparation and Dimethyl Labeling}

Protein samples were separated on a $4 \%-12 \%$ NuPAGE Novex Bis-Tris precast gel (Thermo Fisher Scientific, Waltham, MA, USA) for 8 min at $180 \mathrm{~V}$ in $1 \times$ MES buffer (Thermo Fisher Scientific, Waltham, MA, USA). After protein fixation and coomassie blue staining for protein detection, gels (one slice per sample) were mince and destained in $50 \% \mathrm{EtOH} / 25 \mathrm{mM}$ ammonium bicarbonate (ABC) followed by dehydration in 100\% acetonitrile (ACN). Afterwards a reduction reaction was performed by incubating samples for $1 \mathrm{~h}$ in $10 \mathrm{mM}$ DTT, $50 \mathrm{mM} \mathrm{ABC}$ at $56^{\circ} \mathrm{C}$ followed by an alkylation reaction in alkylation buffer ( $50 \mathrm{mM}$ iodoacetamide (Sigma Aldrich, St. Louis, MO, USA) in $50 \mathrm{mM} \mathrm{ABC}$ ) for $45 \mathrm{~min}$ at room temperature in the dark. Gel slices were washed with 50 mM TEAB buffer $\mathrm{pH} 8.0$ and dehydrated again with ACN. Dried gel pieces were subsequently incubated over night with trypsin solution $(1 \mu \mathrm{g}$ trypsin [Sigma Aldrich, St. Louis, MO, USA]) in 50mM TEAB per sample) at $37^{\circ} \mathrm{C}$. Tryptic peptides were extracted twice with $30 \% \mathrm{ACN}$ and three times with pure ACN. The mixture with the extracted peptides was concentrated in a speed-vac (Eppendorf, Hamburg, Germany) to a final volume of ca. $100 \mu \mathrm{L}$. Dimethyl labeling was performed as described [40,41]. Peptides were either incubated with formaldehyde (Sigma Aldrich, St. Louis, MO, USA) and $\mathrm{NaBH}_{3} \mathrm{CN}$ (Sigma Aldrich, St. Louis, MO, USA) leading to a 28 Da mass-tag (light labeled fraction) or with formaldehyde-d2 (Sigma Aldrich, St. Louis, MO, USA) and $\mathrm{NaBH}_{3} \mathrm{CN}$ resulting in a 32 Da mass-tag (heavy labeled fraction). Heavy labeled peptides from pulldowns with Malat1 fragments were mixed with light-labeled peptides from the control RNA pulldown (forward experiment) and vice versa (reverse experiment).

\subsection{Mass Spectrometry Measurement and Data Analysis}

Peptides were desalted on StageTips [42] and separated on a capillary (New Objective, Woburn, MA, USA) packed with Reprosil C18 (Dr. Maisch GmbH, Ammerbuch-Entringen, Germany). The column was attached to an Easy nLC 1000 system (Thermo Fisher Scientific, San Jose, California, USA) operated with a gradient from $5 \%$ to $60 \%$ acetonitrile in $0.1 \%$ formic acid at a flow of $225 \mathrm{~nL} / \mathrm{min}$. The spray capillary was mounted on the nanospray ion source of a $Q$ Exactive Plus mass spectrometer (Thermo Fisher Scientific, Bremen, Germany). Measurements were using HCD fragmentation with a data-dependent Top10 MS/MS spectra acquisition scheme per MS full scan in the Orbitrap analyzer. The mass spectrometry proteomics data have been deposited to the ProteomeXchange Consortium via the PRIDE [43] partner repository with the dataset identifier PXD017309. The raw files were processed with MaxQuant (version 1.5.2.8) and searched against the mouse UniProt database (54,220 entries). MaxQuant standard settings were used, except dimethyl labels (Lys0, Nter0, Lys4, and Nter4) were defined.

\subsection{Bioinformatics Analysis}

Contaminants, reverse database hits, protein groups only identified by site, and protein groups with less than 2 peptides (at least one of them classified as unique) were removed by filtering from the proteinGroups file. Missing values were imputed by shifting a compressed normal distribution obtained from the LFQ intensity values to the limit of quantitation. The two-dimensional interactions plots were generated from the filtered MaxQuant proteinGroups output file using in-house R scripts [44]. The quantitative data for Figure 2 (zoom) and Supplementary Figure S1 (full) can be retrieved from Supplementary Table S1. Protein localization information were obtained from human orthologues at UniProt [45] or ProteinAtlas [46]. Cluster analysis was performed using the stats package in $\mathrm{R}$ (version 3.4.4). Network analysis and illustration (Figure 4) were performed using the qgraph package in R (version 3.4.4). Figure 3 is based on data provided in Supplementary Table S2. 
Supplementary Materials: Supplementary materials can be found at http://www.mdpi.com/1422-0067/21/3/1166/ s1.

Author Contributions: Conceptualization, F.B and M.Scheibe; methodology, M.S., M.L., F.B., and M.Scheibe; formal analysis, M.S., M.L., F.B., and M.Scheibe; investigation, M.S., M.L., and M.Scheibe.; writing-original draft preparation, M.S., F.B., and M.Scheibe; writing—review and editing, M.L., F.B., and M.Scheibe; supervision, M.Scheibe; funding acquisition, F.B. All authors have read and agreed to the published version of the manuscript.

Funding: The work was funded by the DFG Priority Programme SPP1738 on "Emerging roles of non-coding RNAs in nervous system development, plasticity \& disease" (Bu2996/8-1). The APC was paid by Bu2996/8-1.

Acknowledgments: We thank Anja Freiwald (Proteomics Core Facility at IMB) for technical assistance and Mario Dejung (Proteomics Core Facility at IMB) for bioinformatics support.

Conflicts of Interest: The authors declare no conflict of interest. The funders had no role in the design of the study; in the collection, analyses, or interpretation of data; in the writing of the manuscript, or in the decision to publish the results.

\section{Abbreviations}

CHART-MS capture hybridization analysis of RNA targets and mass spectrometry

ChIRP-MS comprehensive identification of RNA-binding proteins by mass spectrometry

ER endoplasmic reticulum

HyPR-MS multiplexed hybridization purification of RNA-protein complexes for mass spectrometry

lncRNA long non-coding RNA

MS mass spectrometry

RAP-MS RNA antisense purification and mass spectrometry

RBP RNA-binding protein

SILAC stable isotope labeling of amino acids in cell culture

\section{References}

1. Butter, F.; Scheibe, M.; Mörl, M.; Mann, M. Unbiased RNA-protein interaction screen by quantitative proteomics. Proc. Natl. Acad. Sci. USA 2009, 106, 10626-10631. [CrossRef] [PubMed]

2. Scheibe, M.; Butter, F.; Hafner, M.; Tuschl, T.; Mann, M. Quantitative mass spectrometry and PAR-CLIP to identify RNA-protein interactions. Nucleic Acids Res. 2012, 40, 9897-9902. [CrossRef] [PubMed]

3. Castello, A.; Fischer, B.; Eichelbaum, K.; Horos, R.; Beckmann, B.M.; Strein, C.; Davey, N.E.; Humphreys, D.T.; Preiss, T.; Steinmetz, L.M.; et al. Insights into RNA biology from an atlas of mammalian mRNA-binding proteins. Cell 2012, 149, 1393-1406. [CrossRef] [PubMed]

4. Baltz, A.G.; Munschauer, M.; Schwanhäusser, B.; Vasile, A.; Murakawa, Y.; Schueler, M.; Youngs, N.; Penfold-Brown, D.; Drew, K.; Milek, M.; et al. The mRNA-bound proteome and its global occupancy profile on protein-coding transcripts. Mol. Cell 2012, 46, 674-690. [CrossRef] [PubMed]

5. Roth, A.; Diederichs, S. Molecular biology: Rap and chirp about X inactivation. Nature 2015, 521, $170-171$. [CrossRef] [PubMed]

6. West, J.A.; Davis, C.P.; Sunwoo, H.; Simon, M.D.; Sadreyev, R.I.; Wang, P.I.; Tolstorukov, M.Y.; Kingston, R.E. The long noncoding RNAs NEAT1 and MALAT1 bind active chromatin sites. Mol. Cell 2014, 55, 791-802. [CrossRef] [PubMed]

7. McHugh, C.A.; Chen, C.-K.; Chow, A.; Surka, C.F.; Tran, C.; McDonel, P.; Pandya-Jones, A.; Blanco, M.; Burghard, C.; Moradian, A.; et al. The Xist lncRNA interacts directly with SHARP to silence transcription through HDAC3. Nature 2015, 521, 232-236. [CrossRef]

8. Chu, C.; Zhang, Q.C.; da Rocha, S.T.; Flynn, R.A.; Bharadwaj, M.; Calabrese, J.M.; Magnuson, T.; Heard, E.; Chang, H.Y. Systematic discovery of Xist RNA binding proteins. Cell 2015, 161, 404-416. [CrossRef]

9. Giambruno, R.; Mihailovich, M.; Bonaldi, T. Mass Spectrometry-Based Proteomics to Unveil the Non-coding RNA World. Front. Mol. Biosci. 2018, 5, 90. [CrossRef]

10. Ji, P.; Diederichs, S.; Wang, W.; Böing, S.; Metzger, R.; Schneider, P.M.; Tidow, N.; Brandt, B.; Buerger, H.; Bulk, E.; et al. MALAT-1, a novel noncoding RNA, and thymosin beta4 predict metastasis and survival in early-stage non-small cell lung cancer. Oncogene 2003, 22, 8031-8041. [CrossRef]

11. Gutschner, T.; Hämmerle, M.; Diederichs, S. MALAT1-A paradigm for long noncoding RNA function in cancer. J. Mol. Med. 2013, 91, 791-801. [CrossRef] [PubMed] 
12. Li, Z.-X.; Zhu, Q.-N.; Zhang, H.-B.; Hu, Y.; Wang, G.; Zhu, Y.-S. MALAT1: A potential biomarker in cancer. Cancer Manag. Res. 2018, 10, 6757-6768. [CrossRef] [PubMed]

13. Ma, X.-Y.; Wang, J.-H.; Wang, J.-L.; Ma, C.X.; Wang, X.-C.; Liu, F.-S. Malat1 as an evolutionarily conserved lncRNA, plays a positive role in regulating proliferation and maintaining undifferentiated status of early-stage hematopoietic cells. BMC Genom. 2015, 16, 676. [CrossRef] [PubMed]

14. Hutchinson, J.N.; Ensminger, A.W.; Clemson, C.M.; Lynch, C.R.; Lawrence, J.B.; Chess, A. A screen for nuclear transcripts identifies two linked noncoding RNAs associated with SC35 splicing domains. BMC Genom. 2007, 8, 39. [CrossRef] [PubMed]

15. Wilusz, J.E.; Freier, S.M.; Spector, D.L. $3^{\prime}$ end processing of a long nuclear-retained noncoding RNA yields a tRNA-like cytoplasmic RNA. Cell 2008, 135, 919-932. [CrossRef] [PubMed]

16. Zhang, X.; Hamblin, M.H.; Yin, K.-J. The long noncoding RNA Malat1: Its physiological and pathophysiological functions. RNA Biol. 2017, 14, 1705-1714. [CrossRef] [PubMed]

17. Baker, M. Long noncoding RNAs: The search for function. Nat. Methods 2011, 8, 379-383. [CrossRef]

18. Tsai, M.-C.; Manor, O.; Wan, Y.; Mosammaparast, N.; Wang, J.K.; Lan, F.; Shi, Y.; Segal, E.; Chang, H.Y. Long noncoding RNA as modular scaffold of histone modification complexes. Science 2010, 329, 689-693. [CrossRef]

19. Fan, Y.; Shen, B.; Tan, M.; Mu, X.; Qin, Y.; Zhang, F.; Liu, Y. TGF- $\beta$-induced upregulation of malat1 promotes bladder cancer metastasis by associating with suz12. Clin. Cancer Res. 2014, 20, 1531-1541. [CrossRef]

20. Tripathi, V.; Ellis, J.D.; Shen, Z.; Song, D.Y.; Pan, Q.; Watt, A.T.; Freier, S.M.; Bennett, C.F.; Sharma, A.; Bubulya, P.A.; et al. The nuclear-retained noncoding RNA MALAT1 regulates alternative splicing by modulating SR splicing factor phosphorylation. Mol. Cell 2010, 39, 925-938. [CrossRef]

21. Sanford, J.R.; Wang, X.; Mort, M.; Vanduyn, N.; Cooper, D.N.; Mooney, S.D.; Edenberg, H.J.; Liu, Y. Splicing factor SFRS1 recognizes a functionally diverse landscape of RNA transcripts. Genome Res. 2009, 19, 381-394. [CrossRef] [PubMed]

22. Chen, R.; Liu, Y.; Zhuang, H.; Yang, B.; Hei, K.; Xiao, M.; Hou, C.; Gao, H.; Zhang, X.; Jia, C.; et al. Quantitative proteomics reveals that long non-coding RNA MALAT1 interacts with DBC1 to regulate p53 acetylation. Nucleic Acids Res. 2017, 45, 9947-9959. [CrossRef] [PubMed]

23. Spiniello, M.; Knoener, R.A.; Steinbrink, M.I.; Yang, B.; Cesnik, A.J.; Buxton, K.E.; Scalf, M.; Jarrard, D.F.; Smith, L.M. HyPR-MS for Multiplexed Discovery of MALAT1, NEAT1, and NORAD lncRNA Protein Interactomes. J. Proteome Res. 2018, 17, 3022-3038. [CrossRef] [PubMed]

24. Kim, J.; Piao, H.-L.; Kim, B.-J.; Yao, F.; Han, Z.; Wang, Y.; Xiao, Z.; Siverly, A.N.; Lawhon, S.E.; Ton, B.N.; et al. Long noncoding RNA MALAT1 suppresses breast cancer metastasis. Nat. Genet. 2018, 50, 1705-1715. [CrossRef] [PubMed]

25. Cox, J.; Mann, M. MaxQuant enables high peptide identification rates, individualized p.p.b.-range mass accuracies and proteome-wide protein quantification. Nat. Biotechnol. 2008, 26, 1367-1372. [CrossRef] [PubMed]

26. Huttlin, E.L.; Bruckner, R.J.; Paulo, J.A.; Cannon, J.R.; Ting, L.; Baltier, K.; Colby, G.; Gebreab, F.; Gygi, M.P.; Parzen, H.; et al. Architecture of the human interactome defines protein communities and disease networks. Nature 2017, 545, 505-509. [CrossRef] [PubMed]

27. Xu, C.; Yang, M.; Tian, J.; Wang, X.; Li, Z. MALAT-1: A long non-coding RNA and its important 3' end functional motif in colorectal cancer metastasis. Int. J. Oncol. 2011, 39, 169-175. [CrossRef]

28. Yang, F.; Yi, F.; Han, X.; Du, Q.; Liang, Z. MALAT-1 interacts with hnRNP C in cell cycle regulation. FEBS Lett. 2013, 587, 3175-3181. [CrossRef]

29. El Bassit, G.; Patel, R.S.; Carter, G.; Shibu, V.; Patel, A.A.; Song, S.; Murr, M.; Cooper, D.R.; Bickford, P.C.; Patel, N.A. MALAT1 in Human Adipose Stem Cells Modulates Survival and Alternative Splicing of PKC $\delta$ II in HT22 Cells. Endocrinology 2017, 158, 183-195. [CrossRef]

30. Close, P.; East, P.; Dirac-Svejstrup, A.B.; Hartmann, H.; Heron, M.; Maslen, S.; Chariot, A.; Söding, J.; Skehel, M.; Svejstrup, J.Q. DBIRD complex integrates alternative mRNA splicing with RNA polymerase II transcript elongation. Nature 2012, 484, 386-389. [CrossRef]

31. Yu, X.; Wang, M.; Han, Q.; Zhang, X.; Mao, X.; Wang, X.; Li, X.; Ma, W.; Jin, F. ZNF326 promotes a malignant phenotype of breast cancer by interacting with DBC1. Mol. Carcinog. 2018, 57, 1803-1815. [CrossRef] [PubMed] 
32. Latorre, E.; Carelli, S.; Raimondi, I.; D’Agostino, V.; Castiglioni, I.; Zucal, C.; Moro, G.; Luciani, A.; Ghilardi, G.; Monti, E.; et al. The Ribonucleic Complex HuR-MALAT1 Represses CD133 Expression and Suppresses Epithelial-Mesenchymal Transition in Breast Cancer. Cancer Res. 2016, 76, 2626-2636. [CrossRef] [PubMed]

33. Huang, H.; Li, T.; Chen, M.; Liu, F.; Wu, H.; Wang, J.; Chen, J.; Li, X. Identification and validation of NOLC1 as a potential target for enhancing sensitivity in multidrug resistant non-small cell lung cancer cells. Cell. Mol. Biol. Lett. 2018, 23, 54. [CrossRef] [PubMed]

34. Privette Vinnedge, L.M.; McClaine, R.; Wagh, P.K.; Wikenheiser-Brokamp, K.A.; Waltz, S.E.; Wells, S.I. The human DEK oncogene stimulates $\beta$-catenin signaling, invasion and mammosphere formation in breast cancer. Oncogene 2011, 30, 2741-2752. [CrossRef]

35. Chakravarthi, B.V.S.K.; Goswami, M.T.; Pathi, S.S.; Robinson, A.D.; Cieślik, M.; Chandrashekar, D.S.; Agarwal, S.; Siddiqui, J.; Daignault, S.; Carskadon, S.L.; et al. MicroRNA-101 regulated transcriptional modulator SUB1 plays a role in prostate cancer. Oncogene 2016, 35, 6330-6340. [CrossRef]

36. Belkina, A.C.; Denis, G.V. BET domain co-regulators in obesity, inflammation and cancer. Nat. Rev. Cancer 2012, 12, 465-477. [CrossRef]

37. Huang, H.; Zhang, J.; Shen, W.; Wang, X.; Wu, J.; Wu, J.; Shi, Y. Solution structure of the second bromodomain of Brd2 and its specific interaction with acetylated histone tails. BMC Struct. Biol. 2007, 7, 57. [CrossRef]

38. Srisawat, C.; Engelke, D.R. Streptavidin aptamers: Affinity tags for the study of RNAs and ribonucleoproteins. RNA 2001, 7, 632-641. [CrossRef]

39. Bluhm, A.; Viceconte, N.; Li, F.; Rane, G.; Ritz, S.; Wang, S.; Levin, M.; Shi, Y.; Kappei, D.; Butter, F. ZBTB10 binds the telomeric variant repeat TTGGGG and interacts with TRF2. Nucleic Acids Res. 2019, 47, 1896-1907. [CrossRef]

40. Hsu, J.-L.; Huang, S.-Y.; Chow, N.-H.; Chen, S.-H. Stable-isotope dimethyl labeling for quantitative proteomics. Anal. Chem. 2003, 75, 6843-6852. [CrossRef]

41. Boersema, P.J.; Raijmakers, R.; Lemeer, S.; Mohammed, S.; Heck, A.J.R. Multiplex peptide stable isotope dimethyl labeling for quantitative proteomics. Nat. Protoc. 2009, 4, 484-494. [CrossRef]

42. Rappsilber, J.; Mann, M.; Ishihama, Y. Protocol for micro-purification, enrichment, pre-fractionation and storage of peptides for proteomics using StageTips. Nat. Protoc. 2007, 2, 1896-1906. [CrossRef]

43. Perez-Riverol, Y.; Csordas, A.; Bai, J.; Bernal-Llinares, M.; Hewapathirana, S.; Kundu, D.J.; Inuganti, A.; Griss, J.; Mayer, G.; Eisenacher, M.; et al. The PRIDE database and related tools and resources in 2019: Improving support for quantification data. Nucleic Acids Res. 2019, 47, D442-D450. [CrossRef]

44. R: A Language and Environment for Statistical Computing. R Foundation for Statistical Computing; R Core Team: Vienna, Austria, 2014. Available online: http://www.R-project.org (accessed on 10 February 2020).

45. The Uniprot Consortium. UniProt: A worldwide hub of protein knowledge. Nucleic Acids Res. 2019, 47, D506-D515. [CrossRef] [PubMed]

46. Thul, P.J.; Åkesson, L.; Wiking, M.; Mahdessian, D.; Geladaki, A.; Ait Blal, H.; Alm, T.; Asplund, A.; Björk, L.; Breckels, L.M.; et al. A subcellular map of the human proteome. Science 2017, 356, eaal3321. [CrossRef] [PubMed]

(C) 2020 by the authors. Licensee MDPI, Basel, Switzerland. This article is an open access article distributed under the terms and conditions of the Creative Commons Attribution (CC BY) license (http://creativecommons.org/licenses/by/4.0/). 